\title{
Teddy Racer: Lógica de Programação e Ludicidade
}

\author{
Dyego Oliveira Dantas ${ }^{1}$, Isaura Alcina Martins Nobre ${ }^{1}$, Marize Lyra Silva Passos ${ }^{1}$ \\ ${ }^{1}$ Instituto Federal do Espírito Santo (Ifes) \\ Rodovia ES-010 - Km 6,5 - Manguinhos 29173-087 - Serra - ES - Brasil \\ \{dyegod3\}@hotmail.com, \{isaura\}@ifes.edu.br, \{marize\}@ifes.edu.br
}

\begin{abstract}
Knowing the great difficulty of students in higher education in information technology and engineering in the disciplines of algorithms and programming, new objects to support the teaching-learning process have been created in an attempt to make the learning process more enjoyable these disciplines and mitigate the significant numbers of failed students in those disciplines that create a huge bottleneck in the initial phase of these courses, one of the factors responsible for the high dropout rate and delay in the formation of professionals in these areas. This paper presents the learning object "Teddy Racer" which aims to assist in the teaching and learning of the subjects related to programming, aiming to make learning of these subjects a little more fun. The game was developed by applying the XisOA methodology and designed generically enabling educators to manage the kind of knowledge that will be used within the game through configurable Web interface also allows the educator to monitor performance of their students within the game.
\end{abstract}

Resumo. Conhecendo a grande dificuldade dos alunos dos cursos superiores da área de tecnologia da informação e engenharias nas disciplinas de algoritmos e programação, novos objetos para apoiar o processo de ensinoaprendizado têm sido criados na tentativa de tornar o aprendizado dessas disciplinas mais prazeroso e amenizar os expressivos números de alunos desistentes e reprovados nessas disciplinas que geram um enorme gargalo na fase inicial desses cursos, sendo um dos fatores responsáveis pelo alto índice de evasão e atraso na formação de profissionais dessas áreas. Este trabalho apresenta o objeto de aprendizado "Teddy Racer" que visa auxiliar no processo de ensino e aprendizagem das disciplinas relacionadas à lógica de programação, visando tornar a aprendizagem dessas disciplinas um pouco mais lúdica. O jogo foi desenvolvido aplicando a metodologia XisOA e foi projetado de forma genérica possibilitando ao educador gerir o tipo de conhecimento que será utilizado dentro do jogo por meio de interface Web parametrizável, sendo possível também ao educador acompanhar o desempenho de seus alunos dentro do jogo. 


\section{Introdução}

Nos cursos superiores da área de tecnologia da informação e engenharias é comum observar um número expressivo de alunos retidos nos primeiros períodos e um número muito pequeno em fase de conclusão do curso. Um dos gargalos responsáveis pelo alto índice de retenção que impactam também na evasão são as disciplinas de algoritmos e programação (PAIXÃO e KNOBEL, 2012).

Essas disciplinas têm por objetivo desenvolver o raciocínio lógico dos alunos e capacitá-los a resolver problemas expressos em forma de algoritmos. Entre os vários motivos que geram dificuldade aos alunos nessas disciplinas estão: a interpretação dos problemas, o desenvolvimento lógico das soluções, a formalização da solução para uma linguagem de programação, e a simulação do algoritmo em execução (SOLOWAY e EHRLICH, 1984; FALCKEMBACH e ARAÚJO, 2004).

Com o reconhecimento deste problema surgiram muitos estudos para aperfeiçoar o processo de ensino-aprendizagem a fim de tornar o aprendizado destas disciplinas menos traumático e mais prazeroso. O relatório de ensino superior NMC Horizon (2013), destaca que a abordagem de aprendizagem baseada em jogos mostra-se uma ferramenta com grande potencial para alavancar conceitos e simular experiências do mundo real, pois o ato de jogar ajuda a estimular a produção de dopamina, substância que provoca a aprendizagem pelo reforço de conexões e comunicações neurais. Além desse fato, jogos com objetivo educacionais também contribuem para o aprimoramento do pensamento crítico, estimulam soluções criativas e melhoram o trabalho em equipe.

Nesse sentido, este trabalho apresenta o jogo educacional "Teddy Racer" desenvolvido com o objetivo de auxiliar o processo de ensino-aprendizagem das disciplinas introdutórias de programação, visando tornar a aprendizagem mais lúdica e prazerosa.

\section{Ensino de Programação}

Para se desenvolver um programa de computador é necessário analisar e entender o problema a ser resolvido, criar ou escolher uma solução, escrever o algoritmo em uma linguagem de programação, depurar e efetuar testes até que os resultados obtidos cumpram com o objetivo proposto de forma consistente. Isto exige tempo, persistência e disciplina. As etapas mais importantes do trabalho são exatamente as primeiras, onde se cria a solução, por isso os maiores amigos do programador são papel e lápis e não o computador (BINI e KOSCIANSKI, 2009; CARVALHO, 2010).

O estudo de programação tem por objetivo desenvolver um tipo de raciocínio (sequencial e lógico) base para que os alunos se tornem aptos a resolver problemas de várias outras ramificações na informática. A formação deste tipo de raciocínio é necessária aos alunos que desejam obter sucesso durante o curso nas disciplinas que envolvam conceitos e aplicação de programação (CARVALHO, 2010).

Para se alcançar a resolução de um problema é necessário existir uma predisposição ao questionamento, para que haja uma reflexão de quais processos cognitivos devem ser utilizados para se obter o conhecimento necessário para se atingir a solução do problema. Esse processo se dá por meio do pensar, analisar, sintetizar e avaliar (FALCKEMBACH e ARAÚJO, 2004). 


\section{Uso de Jogos na Educação}

Jogos representam brincadeira, entretenimento, passatempo e estão sujeitos às regras que devem ser seguidas, estes podem ser aplicados a inúmeras situações das mais diversas formas (CRISTOVÃO e NOBRE, 2011). Antunes (1998) relata que os jogos podem ser interpretados como estímulo ao crescimento, desenvolvimento cognitivo e aos desafios da vida, e não como uma competição que necessariamente implique em vitória ou derrota.

O jogo educativo traz uma abordagem de aprendizado diferenciada, na qual o jogador vai fazendo descobertas e adquirindo conhecimento por meio de uma exploração autodirigida ao invés da instrução explícita e direta. Os autores que defendem essa filosofia de ensino argumentam que os aprendizes retêm melhor o aprendizado quando são livres para descobrir relações, tornando a atividade de aprender mais prazerosa e divertida. (VALENTE, 1993)

Battaiola (2002) afirma que o sucesso de um jogo não ocorre somente em decorrência de sua interface, mas também de um enredo que proporcione desafios e divertimento ao jogador. Com isso, a abordagem de jogos digitais educativos pretende aproveitar os conceitos de jogabilidade inferido pelos jogos tradicionais e adequar seus conceitos para incorporá-los ao processo de ensino-aprendizagem.

Os jogos digitais educacionais ainda não são amplamente explorados pelos professores, pois a estes encontrar jogos de boa qualidade e que atendam aos requisitos educacionais continua sendo um desafio (BALASUBRAMANIAN e WILSON, 2006). Esse problema ocorre pois muitos jogos educacionais são desenvolvidos por empresas e especialistas no desenvolvimento de jogos tradicionais, que não possuem conhecimentos pedagógicos e específicos a respeito da teoria e prática do uso de jogos em ambientes de aprendizagem. Criam produtos atraentes e divertidos, mas que falham em relação aos objetivos de aprendizagem. Em contrapartida, jogos desenvolvidos por professores e comunidades acadêmicas, são na grande maioria pouco divertidos e não conseguem atrair a atenção dos alunos, já que na maioria dos casos os desenvolvedores não possuem o conhecimento da arte, ciência e cultura de projetos de jogos (ECK, 2006).

Diante desses desafios, fica evidente que os jogos educacionais devem atender tanto a requisitos pedagógicos quanto aos de usabilidade, encontrando a sinergia entre a pedagogia e a diversão para não tornar o jogo um produto "didatizado" que fuja do caráter de entretenimento, ou que atinja somente a recreação (FORTUNA, 2000).

\section{Metodologia XisOA}

A metodologia XisOA, utilizada no desenvolvimento deste trabalho, possui características das metodologias de desenvolvimento de software XP (Extreme Programming), baseada no Modelo RIVED (2009), e foi proposta em 2009 por Nobre e Nascimento que buscavam uma alternativa mais coerente às peculiaridades do desenvolvimento de OAs (Objetos de Aprendizagem).

O modelo de desenvolvimento de OAs proposto por Nobre e Nascimento (2009) pode ser visualizado na Figura 1. 


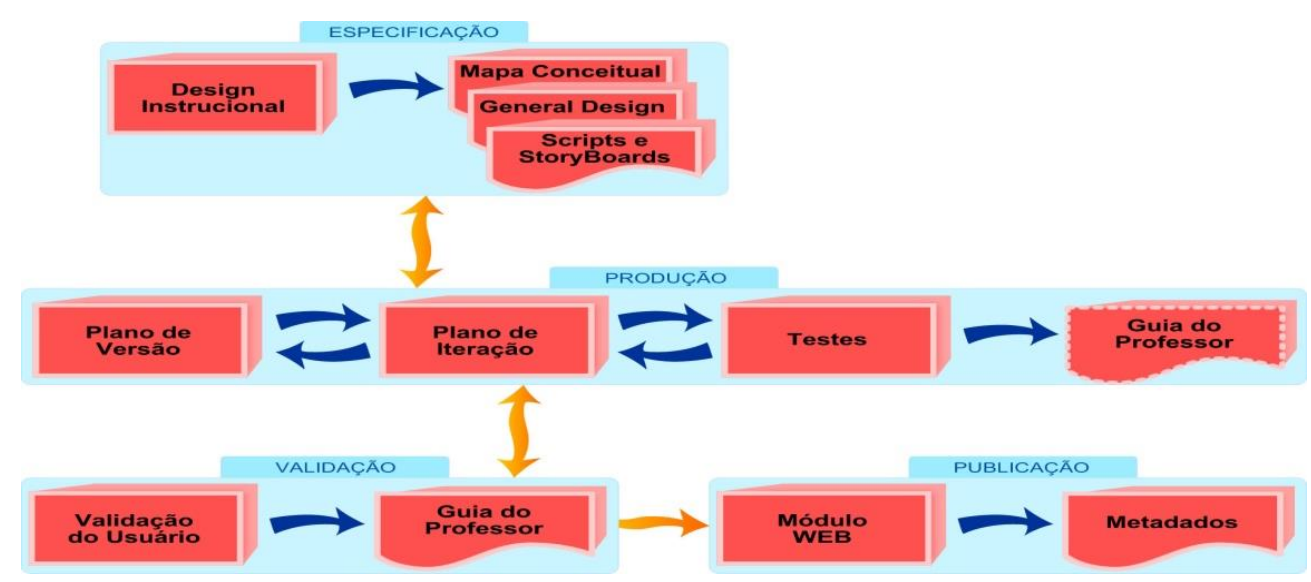

Figura 1 - Metodologia XisOA.

Na etapa de Especificação tem-se o Design Instrucional. Apresentando como artefatos: i) General Design - Descrição geral do projeto, ou seja, objetivos, perfil do usuário, conhecimentos prévios, estratégias pedagógicas, etc.; ii) Scripts e Storyboards - Roteiros e cenários para as telas; iii) Mapa conceitual.

Na Produção do OA tem-se: i) Plano de Versão: Determinação das funcionalidades/atividades que serão desenvolvidas a cada versão, prazos para liberação e prioridade entre as iterações e seus roteiros de testes; ii) Plano de Iteração: Para cada iteração deve ser elaborado um plano de iteração, onde deve-se a cada iteração: planejar, projetar, escrever testes, codificar, testar e integrar; iii) Testes: Ao término de cada iteração, deverão ser realizados testes para verificar a codificação. Como artefatos para essa fase devem ser gerados: versão do OA e do Guia do Professor.

Na Validação se avalia os artefatos gerados, por meio de $i$ ) Validação do usuário e ii) Etapa de Publicação (Módulo Web).

Também são importantes os papeis definidos: Gerente de Projeto; Designer Instrucional; Pedagogo; Professor da área e Desenvolvedor. Entretanto, para o desenvolvimento de um AO, dependendo de sua complexidade, pode-se ter uma mesma pessoa assumindo mais de um papel dentro da equipe.

\section{Processo de Construção do Jogo}

$\mathrm{Na}$ primeira fase do projeto, buscou-se estabelecer e descrever os objetivos que se esperava atingir com o OA, as habilidades, conhecimentos prévios, além das estratégias pedagógicas. Ainda na primeira fase, para se delimitar o escopo do OA e ter uma maior compreensão do problema, foi feito um mapa conceitual do projeto no qual foram definidos os conceitos e seus relacionamentos (Figura 2). 


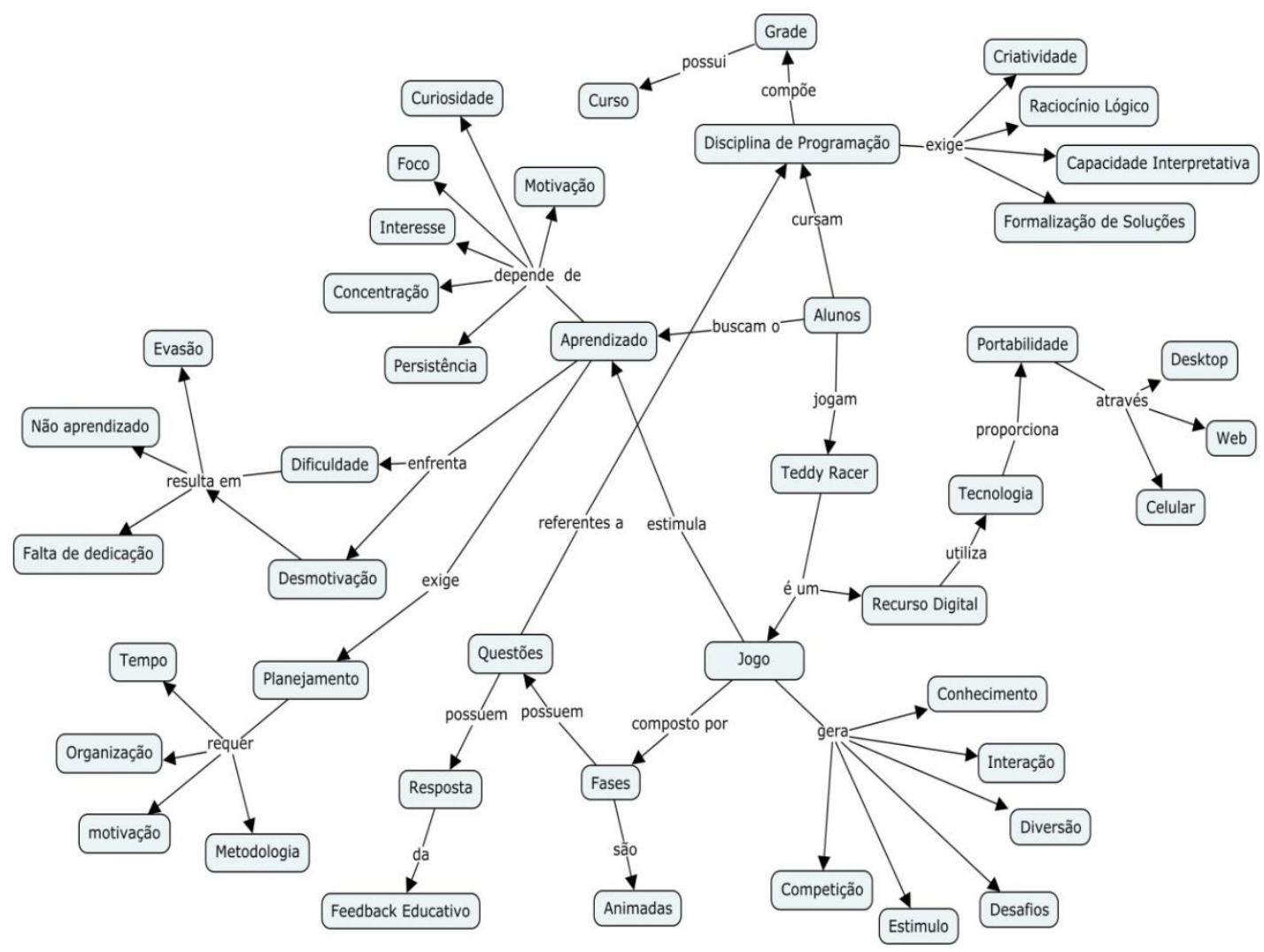

Figura 2 - Mapa Conceitual Projeto

$\mathrm{Na}$ fase de produção do OA foi utilizada a Unity 3D, que é um framework vastamente conhecido por ser poderoso na criação de games, possibilitando a criação de forma ágil e com ótima qualidade. A escolha desse framework também possibilita ao jogo ser executado em multiplataforma. Para a versão web apenas é necessário ao jogador possuir conexão com a Internet e instalar em seu browser o plugin do Unity player. A Unity possibilita ao desenvolvedor trabalhar com um conjunto de linguagens de programação, e neste projeto utilizamos C\# e Javascript. Algumas ferramentas complementares foram utilizadas no processo de desenvolvimento gráfico como o Blender e o adobe Fireworks CS6. De forma paralela à construção do jogo foi construído o módulo web responsável por dispor ao educador função gerencial, neste módulo foram utilizadas tecnologias como PHP, MySQL, HTML5, Javascript e JQuery.

Outro ponto importante, no desenvolvimento desse trabalho foi a implementação de um módulo administrativo, fundamental para que o educador possa gerenciar parametrizações do OA e obter relatórios de desempenho a fim de encontrar pontos críticos e potenciais dentro do escopo de ensino. Este módulo possibilita ainda que o jogo possa ser adaptado para atender a outros conteúdos, podendo dessa forma ser utilizado por professores de diversas disciplinas, bastando para tal que o professor inclua as questões relacionadas ao conteúdo específico, parametrize o grau de dificuldade dentre outros.

\section{O Jogo Teddy Racer}

O jogo Teddy Racer objetiva auxiliar os professores no processo de ensino de programação e dispor ao aluno uma ferramenta de apoio à aprendizagem. 
A base do enredo do jogo consiste na fuga do personagem Teddy de um dinossauro em meio a uma grande floresta tropical, no meio da corrida Teddy ainda precisa saltar sobre obstáculos para não ser capturado. Ao iniciar uma fase é exibido um conjunto de lições relacionadas às questões que serão apresentadas (Figura 3).

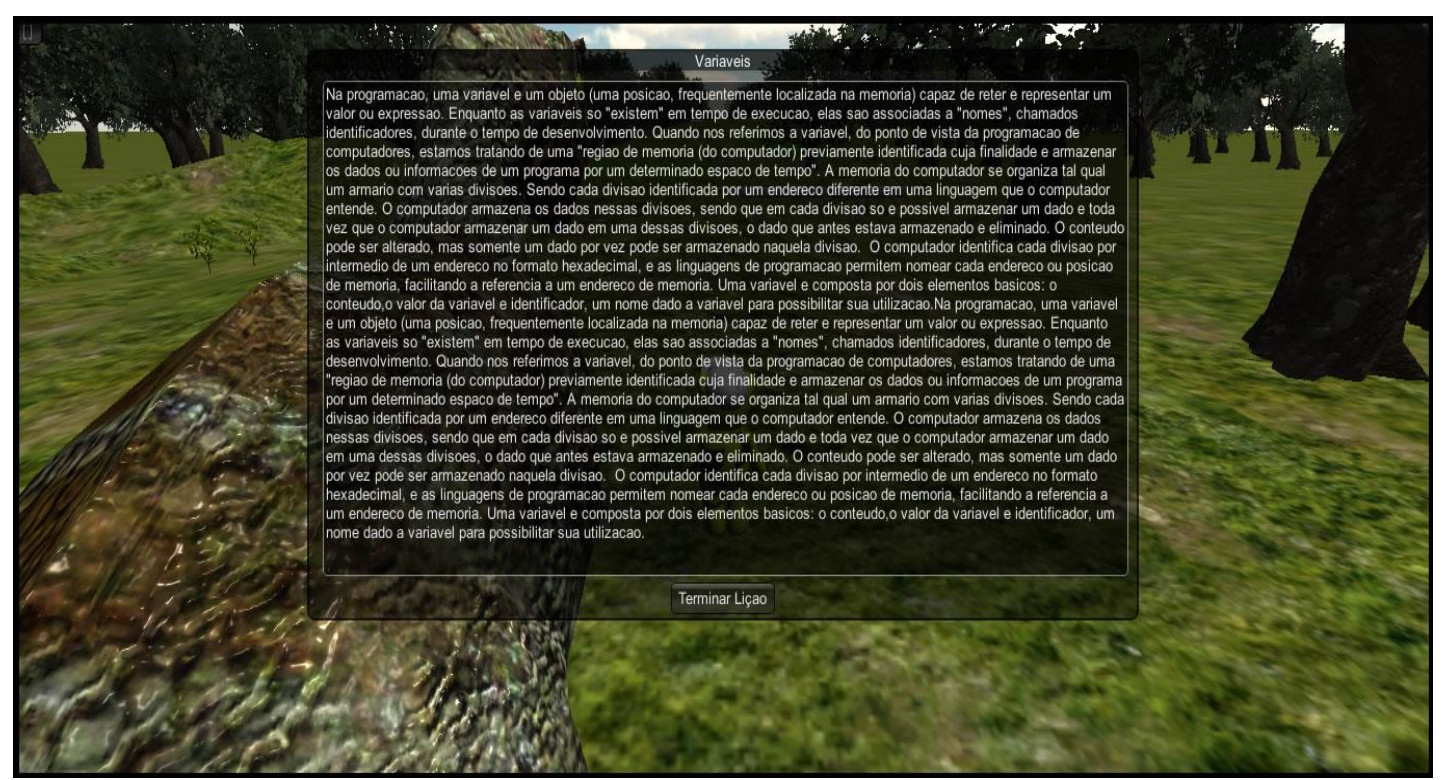

Figura 3 - Cenário onde as lições de jogo são apresentadas.

Após o jogador terminar a leitura das lições o dinossauro aparece para perseguir o ursinho (Figura 4).

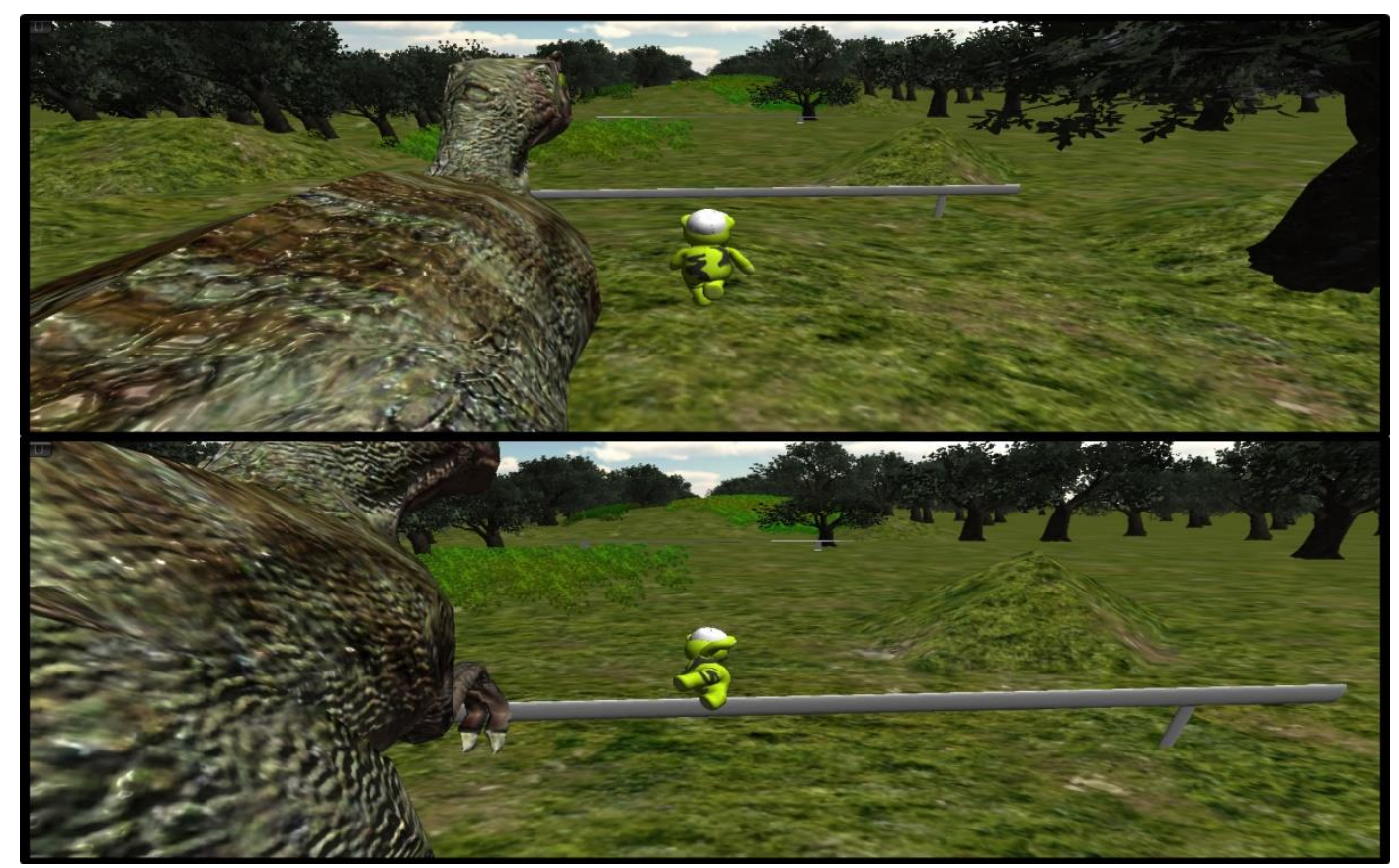

Figura 4 - Cenário onde o dinossauro começa a perseguir o urso Teddy.

A cada ciclo de tempo, questões são apresentadas ao jogador que precisa respondê-las corretamente. A cada erro o personagem Teddy perde velocidade e o dinossauro se aproxima, e com sucessivos erros Teddy é capturado pelo dinossauro 
(Figura 5). Caso o jogador obtenha sucesso ao responder as questões, Teddy ganha muita velocidade e consegue fugir do dinossauro e avançar para o próximo nível.

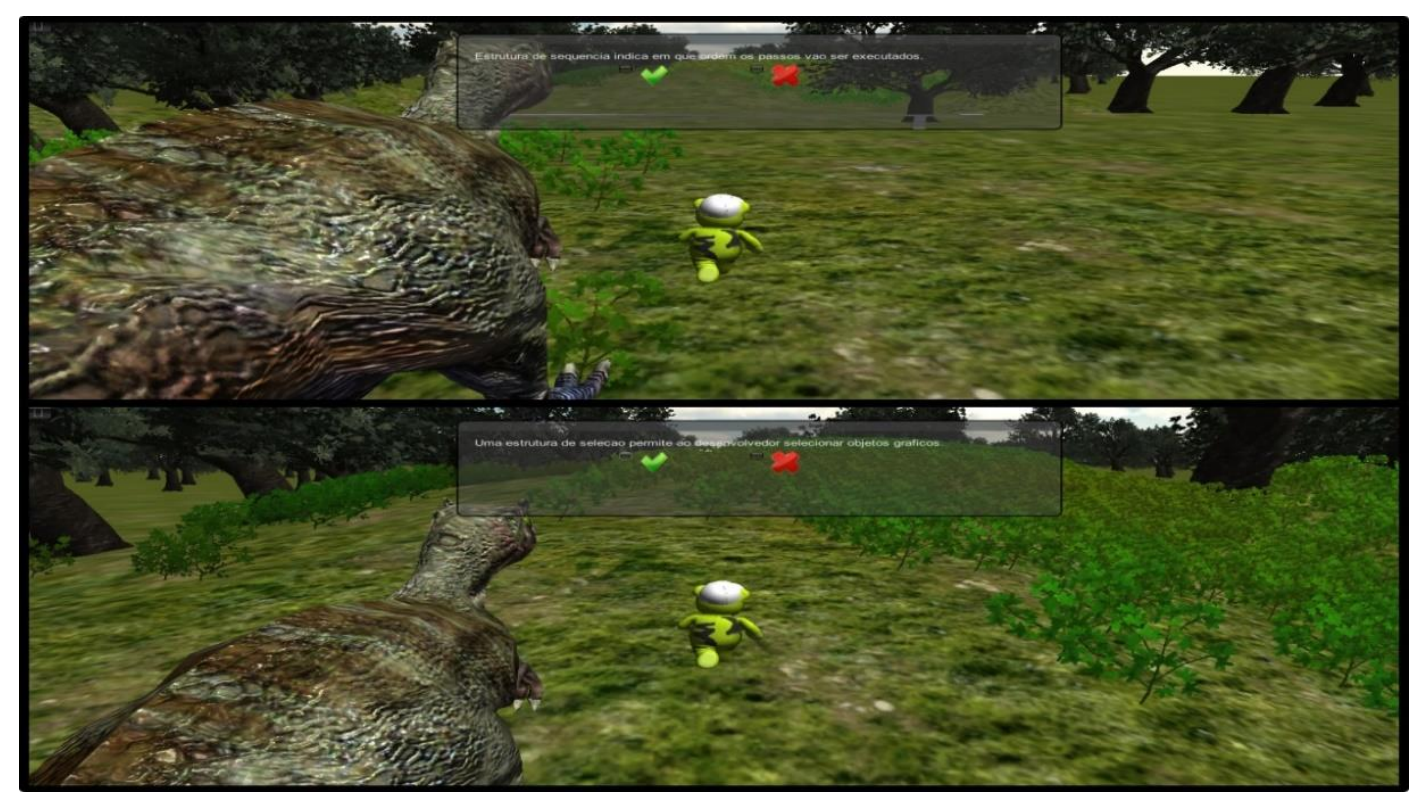

Figura 5 - Questões são apresentadas a Teddy.

As questões apresentadas no jogo são mantidas pelo educador no módulo gerencial disponível para acesso na web, neste é possível cadastrar módulos de ensino, lições, fases e questões, além de possibilitar o acompanhamento dos alunos (Figura 6).

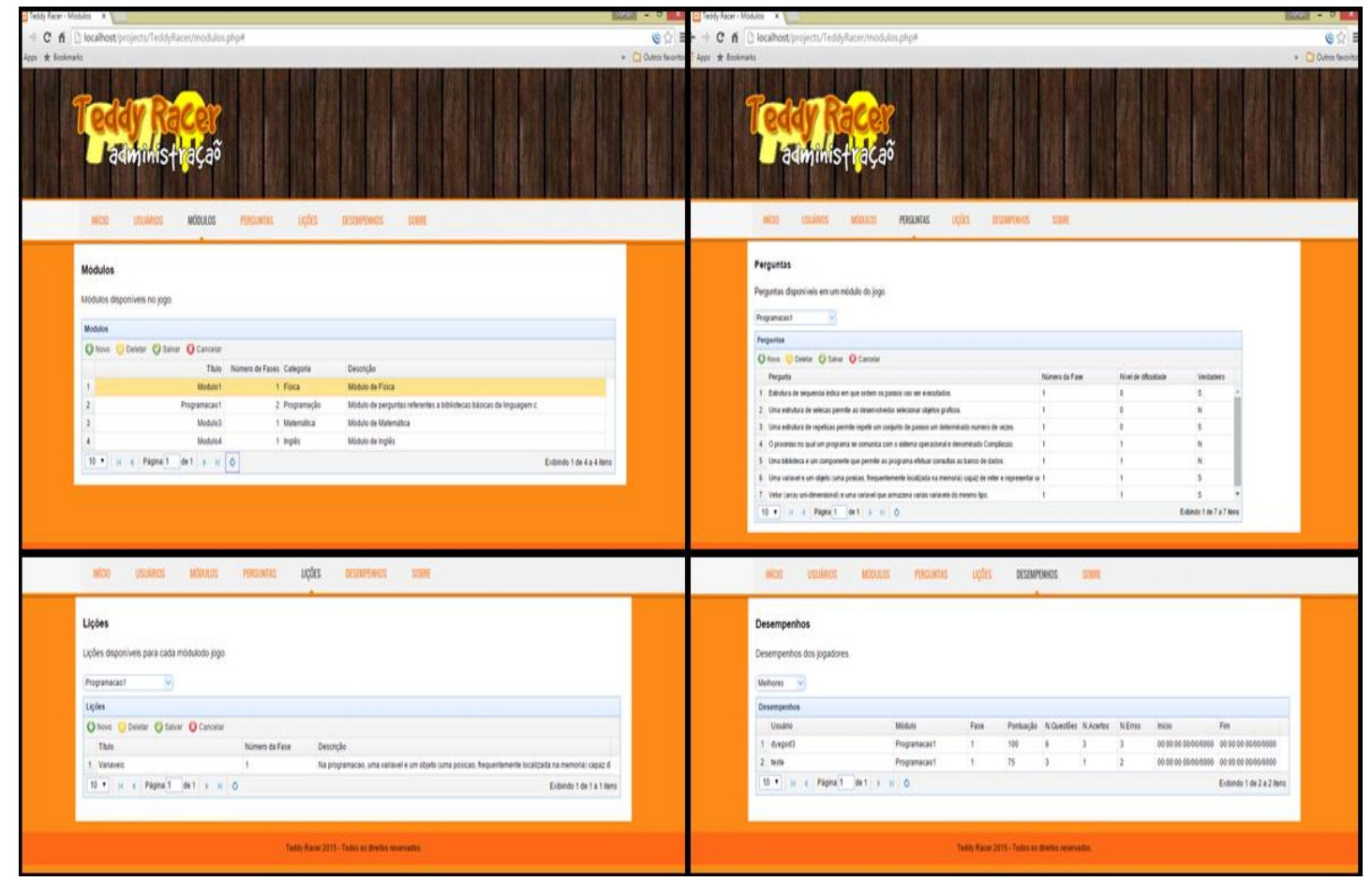

Figura 6 - Módulo gerencial do jogo. 


\section{Validação do Objeto de Aprendizagem}

Para uma melhor análise sobre o impacto educacional do jogo, foram convidados três especialistas, doutores na área de educação com graduação e/ou mestrado em informática, para avaliá-lo. Neste processo foi utilizado um questionário com 17 questões baseado em trabalhos anteriores, destacando requisitos de usabilidade e pedagógicos, tendo como possíveis respostas: atende plenamente, atende parcialmente, não atende e não se aplica. Além disso, foi deixado um espaço para os avaliadores fazerem suas considerações e sugerirem melhorias para o jogo.

Requisitos de usabilidade avaliados foram: a linguagem é adequada ao público alvo definido e ao nível de ensino a que se refere; é atrativo, envolvendo e cativando o aluno em sua utilização; são usadas múltiplas mídias (imagens, animações, vídeos, música etc); o tema é apresentado de forma lúdica e explora uma metáfora esclarecedora para o aluno; permite e incentiva a crescente autonomia e o envolvimento do aluno; o aluno consegue interagir com o programa facilmente; existe interação com outros usuários; promove a criatividade (podem existem vários caminhos/ respostas/ soluções); o tempo de cada ação é adequado. Existe a possibilidade de repetição. As etapas não são exaustivas; as regras são coerentes e estão de acordo com o mundo imaginário proposto; e o nível de concentração exigido está de acordo com o público do jogo.

Requisitos pedagógicos avaliados foram: o conteúdo é coerente e contextualizado com a área e o nível de ensino propostos; o grau de dificuldade é variável, podendo ser definido pelo aluno ou passando de níveis de dificuldade menor para maiores, de acordo com os avanços obtidos; aborda os conteúdos de forma a facilitar o aprendizado; oferece feedbacks construtivos, permitindo ao aluno identificar claramente quando acertou e repensar suas ideias e estratégias quando não forem bem sucedidas; é dado algum incentivo ou premiação ao se atingir certos marcos, a fim de motivar o aluno; e faz referência ao universo cotidiano dos alunos, em uma perspectiva de formação e de cidadania.

Para realizar a avaliação, os especialistas interagiram inicialmente com o jogo sozinhos, sem auxílio da equipe desenvolvedora. Posteriormente, puderam sanar algumas dúvidas e dar sugestões de melhorias.

Pode-se verificar que o jogo teve uma boa avaliação, sendo que dos 17 itens, em onze os avaliadores consideraram que ele atende plenamente e nenhum item foi marcado como "Não atende". Além disso, uma opção foi marcada como "Não se aplica", por não fazerem parte do escopo e propósito do jogo. Porém, quatro itens foram marcados como "Atende parcialmente".

Ao final, os avaliadores contribuíram com algumas sugestões de melhorias: criar mecanismos para incentivar o aluno a continuar jogando, utilizando "achievements"; adicionar mais animações e ou personalizações ao personagem principal do jogo; utilizar padrões aleatórios nas questões, para tornar a aplicação dinâmica e menos monótona; fazer uma importação do aplicativo para Realidade Virtual, utilizando CardBoard como ferramenta e tornando a aplicação mais lúdica, interativa e atraente; possibilitar alterações da temática do jogo de acordo com o público alvo, pois a 
campanha onde o dinossauro persegue um urso indefeso pode ser violenta para crianças; inclusão de medalhas, ou algo parecido, a cada fase vencida; criação de feedbacks mais construtivos quando o jogador errar uma questão; possibilidade de competição - jogo se tornar multiplayer; e possibilitar ao jogador escolher outros personagens, cenários, entre outros fatores que propiciem ao próprio usuário personalizar o jogo.

\section{Conclusões}

Este trabalho apresenta o objeto de aprendizado "Teddy Racer" voltado para apoiar o processo de ensino e tornar a aprendizagem das disciplinas introdutórias de programação um pouco mais divertida. $O$ jogo foi desenvolvido utilizando a metodologia XisOA e projetado de forma genérica possibilitando ao educador gerir o tipo de conhecimento que será utilizado dentro do jogo por meio de interface Web parametrizável, sendo possível também acompanhar o desempenho de seus alunos dentro do jogo.

Uma das grandes dificuldades enfrentadas no decorrer desse trabalho foi o fato de ter apenas um desenvolvedor trabalhando no projeto. Fica claro, que uma equipe integrada com desenvolvedores, professores e pedagogos favorece o alcance dos objetivos, sendo esse um dos principais pontos da metodologia XisOA que busca a integração e troca de informações contínua entre os participantes de um projeto.

$\mathrm{Na}$ fase de produção do OA vale destacar o uso do framework Unity 3D, que além de agilizar a produção do $\mathrm{OA}$, por meio da customização de cenários e personagens, também possibilita ao jogo ser multiplataforma.

Os resultados obtidos por meio das avaliações feitas por especialistas na área de educação com formação também em informática foram satisfatórios, uma vez que os percentuais de aceitação em critérios mais relevantes do ponto de vista pedagógicos, de usabilidade e de aspectos estéticos e lúdicos foram todos positivos. Já, as considerações e sugestões de melhorias elencadas por eles, favorecem a elaboração de propostas para novas versões do objeto em trabalhos futuros.

É importante destacar que este jogo não foi desenvolvido para substituir a metodologia de ensino tradicional de programação, mas para proporcionar aos educadores um método mais dinâmico como apoio ao processo de ensino e aprendizagem.

\section{Referências}

ANTUNES, Celso. Jogos para estimulação das múltiplas inteligências. 10.ed., Petrópolis: Vozes, 1998.

BALASUBRAMANIAN, Nathan; WILSON, Brent G. Games and Simulations. In: Society for information technology and teacher education International conference, 2006. Proceedings. 2006.1 Disponível em: <http://www.coulthard.com/library/Files/balasubramanianwilson_2005gamesandsimulations.pdf>. Acesso em: 07 set. 2015. 
BATTAIOLA, André Luiz et al. Desenvolvimento de um software educacional com base em conceitos de jogos de computador. In: Simpósio Brasileiro de Informática na Educação. 13. 2002, São Leopoldo. Anais. São Leopoldo: UNISINOS, 2002, p. 282-290.

BINI, E. M.; KONSCIANSKI, A. O Ensino De Programação De Computadores Em Um Ambiente Criativo E Motivador. In: VIII Encontro Nacional de Pesquisa Educação em Ciências, 8 nov. 2009, Florianópolis. Anais eletrônicos. Disponível em: $<$ http://posgrad.fae.ufmg.br/posgrad/viienpec/pdfs/675.pdf>. Acessado em: 05/09/2015.

CARVALHO, Victorio Albani. Apostila de Logica de Programação. Colatina, 2010. (Apostila)

ECK, Richard Van. Digital Game-Based Learning: It. Educase Review, v. 41, n. 2, p.16-30, mar. 2006. Disponível em: <http://er.educause.edu/articles/2006/1/digitalgamebased-learning-its-not-just-the-digital-natives-who-are-restless $>$. Acesso em: 07 set. 2015.

NASCIMENTO, E. L.; NOBRE, Isaura A. M. XISOA - Um Processo de Desenvolvimento de Software baseado em Extreme Programming como alternativa para a construção de Objetos de Aprendizagem. In: 15o CIAED (Congresso Internacional ABED de Educação a Distância), Fortaleza, 2009.

NMC Horizon Report, 2013 Higher Education Edition. Disponível em <http://www.nmc.org/pdf/2013-horizon-report-HE.pdf>. Acesso em 29 jun. 2015.

CRISTOVÃO, H. M.; NOBRE, I. Software educativo e objetos de aprendizagem. In: NOBRE, Isaura A. M., NUNES, Vanessa Battestin, GAVA, Tânia B. S., FÁVERO, Rutinelli. P., BAZET, Lydia M. B. Informática na Educação: um caminho de possibilidades e desafios. Editora Ifes: Vitória, 2011

PAIXÃO, F., KNOBEL, M. Tragédia matemática brasileira - O verdadeiro gargalo na formação de engenheiros. Revista Ensino Superior Unicamp. v. 10, p. 40-42, 2012.

SOLOWAY, E.; EHRLICH, K. Empirical Studies of Programming Knowledge. IEEE transactions on software engineering, IEEE Computer Society, v. SE-10, n. 5, p. 595609, Sep. 1984.

VALENTE, José Armando. Diferentes usos do computador na educação. In: VALENTE, J. Armando (Org.). Computadores e conhecimento: repensando a educação. Campinas: NIED/UNICAMP, 1993. 